\title{
Cardiovascular diseases registry (RECVASA): focus on risk factors for stroke in patients with cardiovascular comorbidities
}

M.M.Loukianov ${ }^{1}$, S.Yu.Martsevich ${ }^{1}$, E.Yu.Okshina ${ }^{1}$, S.S.Yakushin², A.N.Vorobyev², A.V.Zagrebelniy ${ }^{1}$, A.D.Deev ${ }^{1}$, A.N.Kozminsky², K.A.Moseichuk², K.G.Pereverzeva², E.A.Pravkina², E.V.Kudryashov¹, E.N.Belova1, O.M.Drapkina1, S.A.Boytsov³

${ }^{1}$ National Medical Research Center for Preventive Medicine, Moscow, Russia

2 Ryazan State Medical University, Ryazan, Russia

3 National Medical Research Center for Cardiology, Moscow, Russia

Aim. To evaluate the risk for stroke in comorbide patients with arterial hypertension (AH), ischemic heart disease (IHD), chronic heart failure (CHF) and atrial fibrillation (AF) enrolled in the outpatient registry RECVASA.

Methods. The RECVASA registry included 3690 patients with cardiovascular diseases (CVD) from 3 outpatient clinics in Ryazan region of Russia. For this analysis, we took patients with the combination of 2-4 CVD (Picture 1). Incidence of non-fatal stroke was estimated during 4-year follow-up period.

Results. 2934 patients were included in our analysis (27.7\% men, age $68.5 \pm 12.9$ years). 326 (11.1\%) patients had history of stroke (HSTR). Mean follow-up was $3.7 \pm 0.9$ years. Lost to follow-up was 4.5\%. 504 (17.2\%) patients died from all causes and 154 (5.2\%) had non-fatal stroke (Table 1). Risk ratio (RR) of non-fatal stroke and 95\% confidential interval (Cl) were analyzed in multifactor Cox model. The next factors had an effect on risk of stroke (Table 2): age - 1.06 (1.05-1.08); HSTR - 3.21 (2.27-4.55); AF-1.94 (1.27-2.96); blood pressure $(B P)<110 / 75 \mathrm{mmHg}-2.72$ (1.02-7.31); heart rate $(H R) \geq 90 / \mathrm{min}-2.10$ (1.23-3.56); administration of ACE inhibitor (ACEI) - 0.54 (0.36-0.80). The next factors had no significant effect on risk of stroke: gender; $\mathrm{BP} \geq 140 / 90 \mathrm{mmHg}$; $\mathrm{AH}$; CHF (NYHA 1-2 and 3-4); IHD; history of myocardial infarction; administration of angiotensine receptor blockers, antithrombotic drugs, beta-blockers; calcium channel blockers, diuretics, statins ( $p>0.05)$.
Picture 1. Cardiovascular comorbidity in patients of RECVASA registry

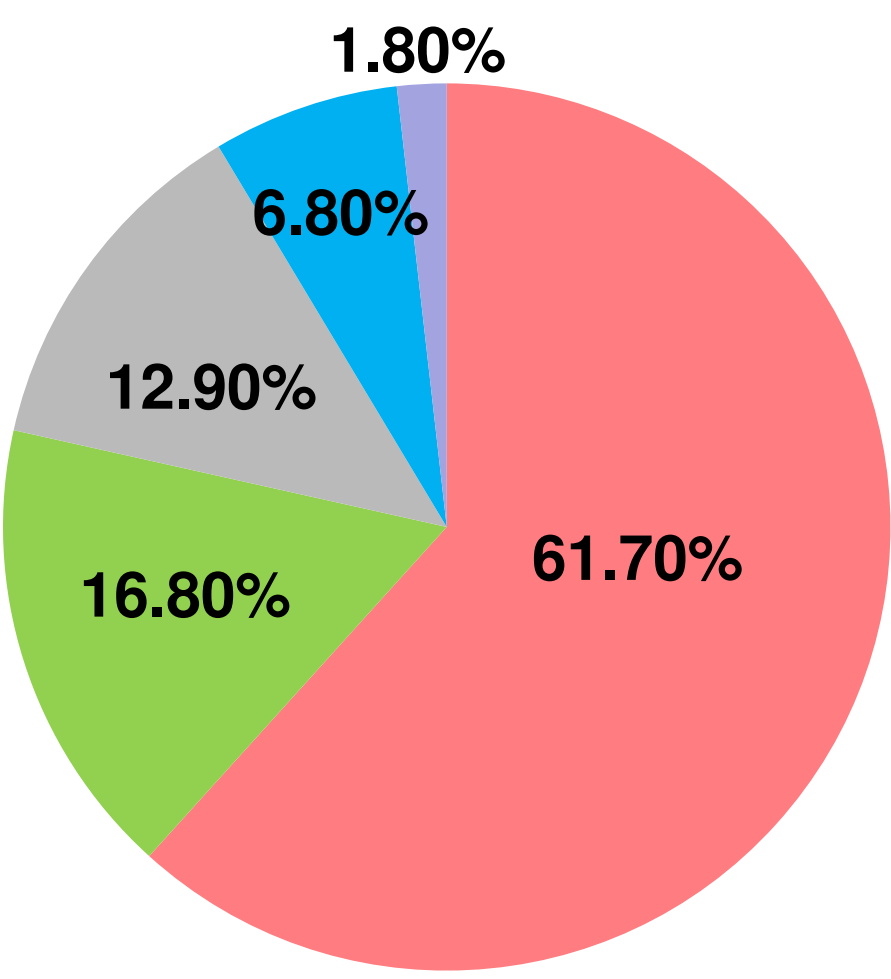

$\square \mathrm{AH}+\mathrm{IHD}+\mathrm{CHF}(\mathrm{n}=1809)$

$\square \mathrm{AH}+\mathrm{IHD}+\mathrm{CHF}+\mathrm{AF}(\mathrm{n}=494)$

$\triangle \mathrm{AH}+\mathrm{CHF}(\mathrm{n}=377)$

- $\mathrm{AH}+\mathrm{IHD}(\mathrm{n}=200)$

Other combinations

$(\mathrm{AH}+\mathrm{AF} ; \mathrm{AH}+\mathrm{IHD}+\mathrm{AF} ;$

$\mathrm{AH}+\mathrm{CHF}+\mathrm{AF} ; \mathrm{n}=54$ )

Table 1. Main characteristics of enrolled patients and outcomes

\begin{tabular}{|l|c|}
\hline Age (years) & $68.5 \pm 12.9$ \\
\hline Gender (m/w,\%) & $27.7 / 72.3$ \\
\hline History of stroke, $\mathrm{n}(\%)$ & $326(11.1 \%)$ \\
\hline Mean number of cardiac comorbidities & $3.0 \pm 0.9$ \\
\hline Follow-up period (years) & $3.7 \pm 0.9$ \\
\hline Lost to follow-up, $\mathrm{n}(\%)$ & $132(4.5 \%)$ \\
\hline Non-fatal stroke, $\mathrm{n}(\%)$ & $154(5.2 \%)$ \\
\hline All cause mortality, $\mathrm{n}(\%)$ & $504(17.2 \%)$ \\
\hline
\end{tabular}

Table 2. Influence of different factors on the risk for stroke in patients with cardiovascular comorbidities

Risk factors

Risk ratio $(95 \% \mathrm{Cl}) \quad{ }^{*}-p<0,01$

History of stroke

$\mathrm{BP}<110 / 75 \mathrm{mmHg}$

Heart rate $(H R) \geq 90 / \mathrm{min}$

Atrial fibrillation

Age

ACEI administration
$3.21(2.27-4.55)^{*}$

$2.72(1.02-7.31)^{*}$

$2.10(1.23-3.56)^{*}$

$1.94(1.27-2.96)^{*}$

$1.06(1.05-1.08)^{*}$

$0.54(0.36-0.80)^{*}$

Conclusions. The RECVASA study revealed during 4-year follow-up period higher risk for stroke in comorbide cardiovascular patients with HSTR, AF, BP<110/75 mm $H R \geq 90 /$ min. In patients with ACEl administration risk for stroke was 1.9 times less. 